\title{
Adherence to Antiretroviral and Cancer Chemotherapy, and Associated Factors Among Patients with HIV-Cancer Co-Morbidity at the Uganda Cancer Institute: A Cross Sectional Study
}

Caroline Achieng ( $\sim$ achiengkcarol86@gmail.com )

Makerere University School of Public Health

Nelson Bunani

Makerere University School of Public Health

Joseph Kagaayi

Makerere University School of Public Health

Fred Nuwaha

Makerere University School of Public Health

\section{Research Article}

Keywords: HIV, Cancer, Comorbidity, Uganda, Chemotherapy.

Posted Date: August 30th, 2021

DOl: https://doi.org/10.21203/rs.3.rs-770283/v1

License: (c) (i) This work is licensed under a Creative Commons Attribution 4.0 International License.

Read Full License 


\section{Abstract}

Background: Human Immunodeficiency Virus is a major global public health issue affecting millions of people, and sub-Saharan Africa where Uganda lies is is disproportionately affected. There has been an increase in cancer among HIV patients which has resulted into use of co-medications that sometimes affect ART and cancer chemotherapy adherence. We aimed to determine adherence to antiretroviral and cancer chemotherapy and the associated factors among patients with HIV-cancer co-morbidity at the Uganda Cancer Institute.

Methods: We conducted a cross-sectional study among 200 randomly selected adult cancer patients infected with HIV, attending Uganda cancer institute. Antiretroviral and anti-cancer chemotherapy adherences with associated factors were assessed quantitatively. We collected the data using interviewer administered semi-structured questionnaires. Modified Poisson regression with robust standard errors was used to estimate prevalence ratios at $95 \%$ confidence intervals for factors associated with adherence to ART and cancer chemotherapy.

Results: Overall, $54 \%$ (107/200) of the study participants adhered to both ART and chemotherapy, and $55 \%$ (110/200) adhered to ART while 65\% (129/200) adhered to cancer chemotherapy. A majority, $61 \%$ $(122 / 200)$ of the respondents were males. The mean age of the respondents was 42 (SD \pm 11 years), and at least $43 \%(86 / 200)$ belonged to protestant religion. More than half, $56.5 \%(113 / 200)$ were married and at least $45 \%(90 / 200)$ had attained a primary level of education. Patients with good adherence to antiretroviral therapy and chemotherapy were $107(54 \%, 95 \% \mathrm{Cl}=46.5-60.4)$. No knowledge of cancer stage $(\mathrm{PR}=0.4,95 \% \mathrm{Cl}=0.25-0.56, \mathrm{P}<0.0001)$, having an AIDS defining cancer $(\mathrm{PR}=0.7,95 \% \mathrm{Cl}=0.50-0.88$, $\mathrm{P}=0.005), A R T$ clinic in district not near Uganda Cancer Institute $(\mathrm{PR}=0.7,95 \% \mathrm{Cl}=0.84-0.96, \mathrm{P}=0.027)$ and affordability of cancer chemotherapy $(P R=1.4,95 \% \mathrm{Cl}=1.02-1.87, \mathrm{P}=0.037)$ were associated with adherence to both ART and cancer chemotherapy.

Conclusion: Adherence to both ART and cancer chemotherapy was low. Factors significantly associated with adherence were: knowledge of the cancer stage by the patient, the type of cancer diagnosis, source of ART and affordability/ availability of medications. There is need to provide information on stage of cancer and adherence counseling to patients. Furthermore, Integration of HIV-cancer care will be necessary for efficient and effective care for the patients.

\section{Background}

Globally, an estimated 37.7 million people were living with HIV in 2020, and about 680,000 died due to AIDS-related illnesses in the same year [1]. Recently, there has been a rise in cancer among the people living with HIV (PLWHIV) with nearly 25-35\% of the global HIV-associated deaths occurring among cancer patients and Sub-Saharan Africa (SSA) bears the greatest burden [2, 3]. People Living with HIV (PLWH) are at an elevated risk of developing cancer [4], and have a higher incidence of both AIDSdefining cancers (ADCs) and non-AIDS-defining cancers (NADCs) due to HIV-induced immunodeficiency 
compared with the general population [5]. Some of the cancers that have been associated with HIV infection include; Kaposi sarcoma is the most common HIV-associated malignancy, followed by cervical cancer, lymphoma and anal cancer, lung cancer and hepatocellular carcinoma [6].

Uganda had an estimated 1.4 million people living with HIV in 2019, and in the same year approximately 23,000 people died of AIDS-related illnesses [7]. The number of documented new cancer cases has increased over the past years in Uganda with approximately 4,000 cancer patients in registered in 2016 and 1,500 cancer-related deaths[8]. Previous studies in Uganda have established an association between HIV infection and cancers with the prevalence ranging from $23-57 \%[9,10]$.

Previous studies have demonstrated that adherence to ART and chemotherapy among HIV-infected cancer patients reduce morbidity associated with opportunistic infections which improves prognosis among these patients [11]. While evidence has found an association between HIV and cancer [10], adherence to medication among cancer patients is sub-optimal. Documented literature elsewhere indicate that adherence to ART and chemotherapy improves patients prognosis [11]. This adherence to care has been associated with; having comorbid conditions, socio-demographic factors, health system factors such as cost of medication, and therapy-related factors such as; the dosing frequency and side effects [12-15].

There is limited data on the ART and chemo adherence in Uganda. Even the available data on ART and cancer chemotherapy has estimated adherence separately. For instance, the average adherence to ART ranges from $50-95 \%[15,16]$ which is lower than the UNAIDS cut off, while adherence to chemotherapy is much lower at $14 \%[17]$. Further still, being on ART and taking cancer chemotherapy increases the pill burden, side effects, toxicity which affect adherence [18]. Data on adherence to ART and cancer chemotherapy as well as the associated factors among HIV-infected cancer patients is limited in Uganda. Yet, high levels of adherence to medications have been found to be predictors of better health-related quality of life among HIV-cancer patients $[10,19]$. We aimed to determine adherence to antiretroviral and cancer chemotherapy and the associated factors among patients with HIV-cancer co-morbidity at the Uganda Cancer Institute. These findings will inform the interventions aimed at improving adherence to care among HIV-cancer patients in Uganda.

\section{Methods}

\section{Study design and setting}

This study utilized a cross sectional study design in which we quantitatively collected data from the patients with HIV-cancer co-morbidity at the Uganda cancer institute $(\mathrm{UCl})$. UCl is a public, specialized, tertiary cancer research and treatment center in Uganda. It is located along upper Mulago Hill road on Mulago Hill, central division, Kampala. It is located about $5 \mathrm{~km}$ North East of the central business district. The UCl provides services on research, training, consultation, prevention and cancer treatment in areas of Pediatrics, Oncology, Gynecology, and Radiotherapy, surgery, pharmacy and recently venturing into bone marrow transplants. The facility has an in-patient's facility with a capacity of 80 beds and receives an 
average of about 200 patients daily. The facility serves approximately 10 million people from Uganda and the neighboring countries of; The democratic Republic of Congo (DRC), Rwanda, Burundi, Tanzania, south Sudan and Kenya.

\section{Study population}

We included a sample of 200 patients who were on both ART and cancer chemotherapy, and attending $\mathrm{UCl}$ in the months of July, August and September 2018. These patients were obtained using simple random sampling, whihch was done through obtaining a list of patients with HIV-cancer co-morbidity from the UCl patient database with the guidance of the UCI data manager. This list was used as a sampling frame from which the study participants were then randomly selected and interviewed for the study using a pre-coded interviewer administered questionnaire. This questionnaire was formulated with guidelines from a tool used to measure adherence to ART with an African resource-constrained setting in South Africa and the WHO five dimensions of adherence [20].

\section{Measures}

The outcome variable was adherence to both ART and chemotherapy. This was measured using a selfreport recall of missed doses method using the four-item Morisky Medication Adherence Scale that has been used in similar studies in South Africa [21]. The Morisky Medication Adherence Scale measures medication adherence by asking the following four questions: (1) Do you sometimes find it difficult to remember to take your medication? (2) Many patients have troubles in taking their medication doses as prescribed; did you miss any doses in the last 7 days? (3) When you feel better, do you sometimes take a break from your medicine? (4) When you feel worse, do you sometimes stop taking your medicine? Adherence was categorized into adherent or not adherent. A patient was considered to be nonadherent if they responded with a 'Yes' to any of the questions. A patient was considered adherent if they said 'No' to all the four questions. Independent variables included; age, sex, education level, marital status, occupation, residence, regimen complexity (ARV complexity and chemotherapy complexity), side effects of the regimen, stage of the cancer, stage of HIV infection and type of cancer.

\section{Data collection and analysis}

Data were collected using a tested questionare [20]. Each questionnaire was given a unique numerical identifier, and all completed questionnaires were locked in the principal investigator's cabinet. The principal investigator (PI) kept the key to the cabinet throughout the study to ensure confidentiality. Data was double entered by trained data entrants. Controls were put in place to rule out any wrong entries or skipped fields. Each questionnaire was thoroughly checked for missing data and errors while still at the data collection area. Data was field edited, coded, cleaned and checked for consistency. Coding was done to clearly identify the required variables for analysis. Data was entered in the EPI-Data version 3.1, transferred to Microsoft excel for cleaning, and then exported to STATA version 15 software for statistical analysis. 


\section{Data analysis}

Data were analyzed using STATA version 15. All continuous variables were summarized using means with their standard deviations (SD) while categorical variables were recoded as proportions. Modified Poisson regression with robust variances was used at bivariable and multivariable analysis to identify factors associated with adherence to ART and cancer chemotherapy. Prevalence ratios (PRs) were used to estimate the strength of association between the outcome and indicator variables and associations were tested at a $95 \%$ confidence interval $(\mathrm{Cl})$. Factors with p-value less than 0.05 at multivariate stage were considered significant.

\section{Results}

\section{Socio-demographic characteristics of the HIV-Cancer comorbidity patients at the Uganda Cancer Institute.}

As depicted in Table 1; of the 200 recruited respondents, 61\% (122/200) were males. The mean age of respondents was $42 \pm 11$ years. More so, $43 \%(86 / 200)$ of the respondents were Protestants and $56.5 \%$ $(113 / 200)$ were married. Table 1 further shows that near half, $45 \%(90 / 200)$ had at least attained a primary education and $40 \%$ (80/200) were in informal-employment. Additionally, more than half, $55.5 \%$ $(111 / 200)$ were from a rural residence.

Table 1: Socio-demographic characteristics of HIV-Cancer comorbidity patients at the Uganda Cancer Institute 


\begin{tabular}{|ll|}
\hline Variable & $\mathrm{n}(\%)$ \\
\hline Age & \\
\hline $18-35$ & $66(33)$ \\
\hline $36-45$ & $74(37)$ \\
\hline $46-55$ & $39(19.5)$ \\
\hline Over 55 years & $21(10.5)$ \\
\hline Sex & \\
\hline Female & $78(39)$ \\
\hline Male & $122(61)$ \\
\hline Religion & \\
\hline Catholic & $74(37)$ \\
\hline Protestant & $86(43)$ \\
\hline Muslim & $32(16)$ \\
\hline Others* & $8(4)$ \\
\hline Marital status & \\
\hline Single & $46(23)$ \\
\hline Married & $113(56.5)$ \\
\hline Divorced & $25(12.5)$ \\
\hline Others** & $16(8)$ \\
\hline Level of education & \\
\hline None & $28(14)$ \\
\hline Primary & $90(45)$ \\
\hline Secondary & $60(30)$ \\
\hline Tertiary & $22(11)$ \\
\hline Occupation & \\
\hline None & \\
\hline Peasant & \\
\hline Self Employed & \\
\hline Employed & \\
\hline
\end{tabular}




\begin{tabular}{|ll|} 
Residence & \\
\hline Rural & $111(55.5)$ \\
\hline Urban & $89(44.5)$ \\
\hline
\end{tabular}

Others religions included; born again, orthodox, Seventh day Adventists and Jehovah's Witness.

Other marital status included; separated, widowed and not living together.

Adherence to ART and cancer chemotherapy

More than half, 54\% (107/200) of the respondents adhered to both ART and chemotherapy. Additionally, $55 \%(110 / 200)$ adhered to ART and 65\% (129/200) adhered to chemotherapy. See Table 2.

Table 2: Adherence to ART and Cancer Chemotherapy among patients with HIV-Cancer comorbidity at the Uganda Cancer Institute

\begin{tabular}{|lllll|}
\hline Outcome & Frequency $(\mathbf{n = 2 0 0 )}$ & Percentage (\%) & \multicolumn{2}{l|}{$\mathbf{9 5 \%} \mathbf{C l}$} \\
\hline ART Adherence & 110 & 55 & 48.0 & 61.8 \\
\hline CHEMO Adherence & 129 & 65 & 57.6 & 70.9 \\
\hline Overall Adherence & 107 & 54 & 46.5 & 60.4 \\
\hline
\end{tabular}

Multivariable analysis of the factors associated with adherence to ART and chemotherapy among HIV cancer patients attending Uganda cancer institute

Knowledge of cancer stage, type of cancer diagnosis, source of ARVs and affordability of cancer chemotherapy were significantly associated with adherence to ART and cancer chemotherapy. Respondents who did not know their cancer stage (APR=0.4, 95\% $\mathrm{Cl}=0.25-0.56, \mathrm{P}<0.0001)$ were 0.4 times less likely to adhere to their treatments than those in the early stage; Patients with AIDS defining cancers (APR 0.7, 95\% Cl=0.50-0.88, $\mathrm{P}=0.005$ ) were 0.7 times less likely to adhere to both ART and cancer chemotherapy than those with NADCs. ART clinic near UCl was associated with better adherence to the medications (APR $=0.7,95 \% \mathrm{Cl}=0.84-0.96, \mathrm{P}$-value $=0.027$ ). Cancer chemotherapy affordability was positively significant to adherence (APR $1.4,95 \% \mathrm{Cl}=0.02-0.87$, P-value=0.037). See Table 3.

Table 3: Factors associated with adherence to ART and chemotherapy among HIV cancer patients attending Uganda cancer institute 


\begin{tabular}{|c|c|c|c|c|c|c|c|c|}
\hline \multirow[t]{2}{*}{ Variable } & \multicolumn{2}{|c|}{$\begin{array}{l}\text { Adherence } \\
(n=107)\end{array}$} & \multicolumn{2}{|c|}{$\begin{array}{l}\text { Non- } \\
\text { Adherence } \\
(\mathrm{n}=93)\end{array}$} & \multirow[t]{2}{*}{$\begin{array}{l}\text { UPR } \\
(95 \% \mathrm{Cl})\end{array}$} & \multirow[t]{2}{*}{$\begin{array}{l}\mathrm{P}- \\
\text { value }\end{array}$} & \multirow[t]{2}{*}{$\begin{array}{l}\text { APR } \\
(95 \% \\
\text { Cl) }\end{array}$} & \multirow[t]{2}{*}{$\begin{array}{l}\text { P- } \\
\text { Value }\end{array}$} \\
\hline & n & $\%$ & $\mathbf{n}$ & $\%$ & & & & \\
\hline \multicolumn{9}{|l|}{ Sex } \\
\hline Male & 63 & 58.9 & 59 & 63.4 & 1 & & 1 & \\
\hline Female & 44 & 41.1 & 34 & 36.6 & $\begin{array}{l}1.1(0.84- \\
1.42)\end{array}$ & 0.506 & $\begin{array}{l}0.8 \\
(0.60- \\
1.01)\end{array}$ & 0.056 \\
\hline \multicolumn{9}{|l|}{ Side effects } \\
\hline Yes & 78 & 72.9 & 75 & 80.6 & 1 & & 1 & \\
\hline No & 29 & 27.1 & 18 & 19.4 & $\begin{array}{l}1.2(0.92- \\
1.59)\end{array}$ & 0.173 & $\begin{array}{l}1.1 \\
(0.80- \\
1.40)\end{array}$ & 0.705 \\
\hline \multicolumn{9}{|c|}{$\begin{array}{l}\text { Knowledge of cancer } \\
\text { stage }\end{array}$} \\
\hline Early & 49 & 45.8 & 21 & 22.6 & 1 & & 1 & \\
\hline Late & 36 & 33.6 & 12 & 12.9 & $\begin{array}{l}1.1(0.86- \\
1.34)\end{array}$ & 0.547 & $\begin{array}{l}0.9 \\
(0.67- \\
1.10)\end{array}$ & 0.239 \\
\hline Unknown & 22 & 20.6 & 60 & 64.5 & $\begin{array}{l}0.4(0.26- \\
0.57)\end{array}$ & $0.000 *$ & $\begin{array}{l}0.4 \\
(0.25- \\
0.56)\end{array}$ & $0.000 *$ \\
\hline \multicolumn{9}{|l|}{ Cancer diagnosis } \\
\hline Non-AIDs defining & 40 & 37.4 & 18 & 19.4 & 1 & & 1 & \\
\hline AIDs defining & 67 & 62.6 & 75 & 80.6 & $\begin{array}{l}0.5(0.40- \\
0.51)\end{array}$ & $0.000 *$ & $\begin{array}{l}0.7 \\
(0.50- \\
0.88)\end{array}$ & $0.005^{\star}$ \\
\hline \multicolumn{9}{|c|}{$\begin{array}{l}\text { Last time that missed } \\
\text { taking pills }\end{array}$} \\
\hline Ever missed & 22 & 20.6 & 40 & 43 & 1 & & 1 & \\
\hline Never missed & 85 & 79.4 & 53 & 57 & $\begin{array}{l}1.7(1.21- \\
2.49)\end{array}$ & $0.003^{*}$ & $\begin{array}{l}0.93- \\
1.47\end{array}$ & 0.125 \\
\hline \multicolumn{9}{|l|}{$\begin{array}{l}\text { Ever missed } \\
\text { appointment dates }\end{array}$} \\
\hline Yes & 29 & 27.1 & 42 & 45.2 & 1 & & 1 & \\
\hline No & 78 & 72.9 & 51 & 54.8 & $\begin{array}{l}1.5(1.08- \\
2.03)\end{array}$ & $0.014^{*}$ & $\begin{array}{l}1.1 \\
(0.84-\end{array}$ & 0.473 \\
\hline
\end{tabular}




\section{Source of ARVs}

\begin{tabular}{|c|c|c|c|c|c|c|c|c|}
\hline ART clinic nearby UCI & 13 & 12.1 & 20 & 21.5 & 1 & & 1 & \\
\hline ART clinic near home & 59 & 55.1 & 70 & 75.3 & $\begin{array}{l}1.2(0.73- \\
1.85)\end{array}$ & 0.529 & $\begin{array}{l}0.7 \\
(0.84- \\
0.96)\end{array}$ & 0.027 * \\
\hline Other & 35 & 32.7 & 3 & 3.2 & $\begin{array}{l}2.3(1.51- \\
3.61)\end{array}$ & $0.000 *$ & $\begin{array}{l}0.9 \\
(0.61- \\
1.44)\end{array}$ & 0.759 \\
\hline \multicolumn{9}{|l|}{$\begin{array}{l}\text { Chemotherapy } \\
\text { affordable? }\end{array}$} \\
\hline No & 35 & 32.7 & 65 & 69.9 & 1 & & & \\
\hline Yes & 72 & 67.3 & 28 & 30.1 & $\begin{array}{l}2.1(1.53- \\
2.76)\end{array}$ & $0.000 *$ & $\begin{array}{l}1.4 \\
(0.02- \\
0.87)\end{array}$ & $0.037 *$ \\
\hline
\end{tabular}

\section{*= Statistically significant ( $P$-value $<0.05)$, UPR= unadjusted prevalence ratio, APR=adjusted prevalence ratio, $\mathrm{Cl}=$ confidence interval.}

\section{Discussion}

We found adherence to both ART and cancer chemotherapy at 54\%. Adherence to ART alone in HIVcancer patients was $55 \%$ while that of cancer chemotherapy alone was $(65 \%)$. These findings are lower than those in a related previous study conducted in Uganda [15]. These findings could be different because of the presence of the co-morbidity of HIV and cancer where one ailment could affect the adherence to the other. Comparable findings were reported by Greer, Amayol et al in their study where they found rates of adherence to cancer chemotherapy varying from as low as $46 \%$ [22]. These findings are also in-line with a review study for adherence in chronic illness that stated that achieving adherence rates above $80 \%$ is difficult even in resource - rich countries [23].

Our study found that individuals who did not know their stage of cancer were less likely to adhere well to both their ART and cancer chemotherapy. This could be because knowledge of one's cancer stage contributes to the way they adhere to medications. It is important for the patients to know whether the cancer is in an early or late stage so as to plan on medication in time. These findings are different from those in studies that found late cancer stage [24, 25], associated with poor adherence [26-28], and another study that found patients with metastatic cancer more likely to become over-adherent to oral chemotherapy [27].

Our study further found the type of cancer diagnosis significantly associated with ART and cancer chemotherapy adherence. Individuals with the AIDS defining cancers such as Kaposi's sarcoma, Non Hodgkins lymphoma were less likely to adhere well to their co- medications. These findings suggest that 
patients with advanced HIV disease or AIDS may not adhere well to their medications; this could be explained by the high pill burden, and possibly because of the presence of other comorbidities which may hinder proper adherence to medications.

Accessing ART from a clinic near UCl was found to be positively associated with both ART and cancer chemotherapy than picking ART from in district away from UCl. This could be because the patients find it easy to access the both treatments since the ART treatment Centre and cancer treatment Centre are near each other. Our study found that affordability of chemotherapy to be positively associated with ART and chemotherapy adherence. This is explained by the fact that, at Uganda Cancer Institute most of the chemotherapy is given at a free cost and patients only buy the drugs if they are out of stock. These findings are comparable to those in studies that found supplying medication to patients from the health facility improved medication adherence, and reducing patient out-of-pocket expenses was associated with improved drug adherence [29]. Therapies that are high-value on high-risk patients like those with the HIV-cancer comorbidity may affect adherence and lead to undesired adherence and health outcomes [29].

The study found that the patients with both HIV and cancer on both ART and cancer chemotherapy generally felt weak most of the times, experienced a number of treatment challenges including drug side effects, missing their doses, stigma and financial challenges. They experienced a number of hospital visits and hospital admissions. These findings are similar to those in other studies that found disease correlates, such as the number of co morbidities, cancer stage, and nodal involvement, associated with negative medication adherence [24, 25], also treatment factors, such as higher doses of medication, worse side effects, switching therapy types, and higher utilization of medical care were associated with poor adherence [26, 27].

\section{Strength and limitations}

This study collected primary data from the patients with HIV and cancer, which was considered reliable information from which adherence was measured. The method (Moriscky scale) used to estimate adherence was a reliable and it validated tool.

Due to limited time and resources, our study did not assess the level of adherence per specific type of cancer which could have overestimated the outcome. Future studies will be necessary to determine the level of adherence to ART and Cancer chemotherapy per specific type of cancer.

\section{Conclusion And Implications}

Overall, adherence to both ART and cancer chemotherapy was low. Factors that were found to be associated with adherence were; Knowledge of the cancer stage by the patient, the type of cancer diagnosis, source of ART and affordability of the medications. Our findings suggest a need health promotion awareness campaigns and adherence counseling to increase knowledge of cancer stages and adherence among patients with cancer and HIV-comorbidity. Furthermore, there is need to integrate free and/ or subsidized HIV treatment services with cancer care services to ease access by the patients. 


\section{Abbreviations}

\begin{tabular}{|ll|}
\hline UCI & Uganda Cancer Institute \\
\hline IRB & Institutional Review Board \\
\hline HDREC & Higher Degrees Research and Ethics Committee \\
UBOS & Uganda Bureau of Statistics \\
MOH & Ministry of Health \\
\hline
\end{tabular}

\section{Declarations}

\section{Ethics approval and consent to participate}

We obtained ethical approval to conduct the study from Makerere University School of Public Health Higher Degrees Research and Ethics Committee (HDREC) and Uganda Cancer institute Institutional Review Board (IRB). The study was performed in accordance with the ethical standards as laid down in the 1964 Declaration of Helsinki. Informed voluntary consent was sought from the participants. They were assured of privacy and confidentiality of the information collected by leaving the questionnaires anonymous and no personal identifiers were used. The aims of the study were well explained to study participants and those that accepted to take part in the study were requested to sign a written consent form.

\section{Consent for publication}

Not applicable.

\section{Availability of data and material}

The data used and/or analyzed during the study are available from the corresponding author upon reasonable request.

\section{Competing interests}

The authors declare that they have no competing interests.

\section{Funding}

The authors did not receive any particular funding for this study.

\section{Authors' contributions}

C.A led the conceptualization of the first draft of the study. C. A and N.B contributed towards literature search, data analysis, and drafting of the first version of the manuscript. J.K and F.N offered guidance 
and contributed towards reviewing the initial drafts of the manuscript. All authors contributed to data interpretation and critical comments on the first and subsequent drafts of the manuscript. All authors read and approved the final manuscript for submission.

\section{Acknowledgements}

We acknowledge the support by the data collectors and the study participants who accepted to take part in this study. We are indebted to Makerere University School of Public Health, Research and Ethics Committee for giving us ethical approval. We also thank the management of Uganda Cancer Institute for giving us the permission to access the study participants.

\section{References}

1. UNAIDS, Global HIV \& AIDS statistics - 2021 fact sheet. 2021 [cited 2020 14th June]; Available from: https://www.unaids.org/sites/default/files/media_asset/UNAIDS_FactSheet_en.pdf. 2020.

2. Anampa, J., et al., Human Immunodeficiency Virus (HIV) Infection and Cancer, in Abeloff's Clinical Oncology. 2020, Elsevier. p. 894-903. e4.

3. UNAIDS, 'AIDSinfo' (accessed August 2019). 2019.

4. Chen, C.-H., et al., Risk of cancer among HIV-infected patients from a population-based nested casecontrol study: implications for cancer prevention. BMC cancer, 2015. 15: p. 133-133.

5. Jin, Z.-Y., et al., Cancer risk factors among people living with HIV/AIDS in China: a systematic review and meta-analysis. Scientific reports, 2017. 7(1): p. 1-15.

6. Casper, C., et al., HIV/AIDS comorbidities: impact on cancer, noncommunicable diseases, and reproductive health. 2017.

7. UNAIDS. AIDSinfo. 2019 [cited 2020 14th June]; Available from: http://aidsinfo.unaids.org/.

8. (UCI), U.C.I., New Cancer incidences at the Uganda Cancer Institute. 2017, Uganda Cancer Institute: Kampala.

9. Menon, M., et al., Whom to treat? Factors associated with chemotherapy recommendations and outcomes among patients with NHL at the Uganda Cancer Institute. PLOS ONE, 2018. 13(2): p. e0191967.

10. Menon, M.P., et al., Association Between HIV Infection and Cancer Stage at Presentation at the Uganda Cancer Institute. Journal of Global Oncology, 2018(4): p. 1-9.

11. Torres, H.A. and V. Mulanovich, Management of HIV Infection in Patients With Cancer Receiving Chemotherapy. Clinical Infectious Diseases, 2014. 59(1): p. 106-114.

12. Yeam, C., et al., A systematic review of factors affecting medication adherence among patients with osteoporosis. Osteoporosis International, 2018. 29(12): p. 2623-2637.

13. Greer, J.A., et al., A Systematic Review of Adherence to Oral Antineoplastic Therapies. The Oncologist, 2016. 21(3): p. 354-376. 
14. Mitiku, H., T. Abdosh, and Z. Teklemariam, Factors Affecting Adherence to Antiretroviral Treatment in Harari National Regional State, Eastern Ethiopia. ISRN AIDS, 2013. 2013: p. 960954.

15. Nabukeera-Barungi, N., et al., Adherence to antiretroviral therapy and retention in care for adolescents living with HIV from 10 districts in Uganda. BMC Infectious Diseases, 2015. 15: p. 520.

16. Burua, A., F. Nuwaha, and P. Waiswa, Adherence to standards of quality HIV/AIDS care and antiretroviral therapy in the West Nile Region of Uganda. BMC Health Services Research, 2014. 14(1): p. 521.

17. Barillet, M., et al., Oral antineoplastic agents: how do we care about adherence? British Journal of Clinical Pharmacology, 2015. 80(6): p. 1289-1302.

18. Partridge, A.H., et al., Adherence and Persistence With Oral Adjuvant Chemotherapy in Older Women With Early-Stage Breast Cancer in CALGB 49907: Adherence Companion Study 60104. Journal of Clinical Oncology, 2010. 28(14): p. 2418-2422.

19. Drzayich Antol, D., et al., The relationship between comorbidity medication adherence and health related quality of life among patients with cancer. Journal of patient-reported outcomes, 2018. 2: p. 29-29.

20. WHO, adherence to long term therapies. Evidence FOR action. 2003, GENEVA: World Health Organisation, Amazon .com.

21. Morisky, D., L. Green, and D. M. Levine, Concurrent and Predictive-Validity of A Self-Reported Measure of Medication Adherence. Vol. 24. 1986. 67-74.

22. Greer, J.A., et al., A Systematic Review of Adherence to Oral Antineoplastic Therapies. Oncologist, 2016. 21(3): p. 354-76.

23. DiMatteo, M.R., Variations in patients' adherence to medical recommendations: a quantitative review of 50 years of research. Med Care, 2004. 42(3): p. 200-9.

24. Makanjuola, T., H.B. Taddese, and A. Booth, Factors Associated with Adherence to Treatment with Isoniazid for the Prevention of Tuberculosis amongst People Living with HIV/AIDS: A Systematic Review of Qualitative Data. PLoS ONE, 2014. 9(2): p. e87166.

25. Lohmann, A., et al., Adherence to adjuvant hormone therapy (AHT) in early breast cancer (BC). Journal of Clinical Oncology, 2013. 31(15_suppl): p. e11522-e11522.

26. lihara, $\mathrm{H}$., et al., Control of chemotherapy-induced nausea in patients receiving outpatient cancer chemotherapy. International Journal of Clinical Oncology, 2016. 21: p. 409-418.

27. Patel, K., et al., Oral Cancer Chemotherapy Adherence and Adherence Assessment Tools: A Report from North Central Cancer Group Trial N0747 and a Systematic Review of the Literature. Journal of cancer education : the official journal of the American Association for Cancer Education, 2013. 28(4): p. 10.1007/s13187-013-0511-z.

28. Bourmaud, A., et al., Adherence to oral anticancer chemotherapy: What influences patients' over or non-adherence? Analysis of the OCTO study through quantitative-qualitative methods. BMC research notes, 2015. 8(1): p. 291. 
29. González López-Valcárcel, B., et al., Effect of cost sharing on adherence to evidence-based medications in patients with acute coronary syndrome. Heart, 2017. 103(14): p. 1082. 